\title{
Medicinal properties of some Dendrobium orchids - A review
}

\author{
T. Ramesh ${ }^{* 1}$, M. Koperuncholan ${ }^{1}$, R. Praveena ${ }^{1}$, K. Ganeshkumari ${ }^{1}$, J. Vanithamani ${ }^{1}$, P. Muruganantham ${ }^{1}$ \\ P. Renganathan ${ }^{2}$ \\ ${ }^{1}$ Department of Botany, Srimad Andavan Arts and Science College (Autonomous) Tiruchirappalli-620005, Tamil Nadu, India \\ ${ }^{2}$ Department of Botany (DDE), Annamalai University Annamalainagar - 608 002, Tamil Nadu, India
}

(Received: 19-01-2019; Accepted 22-08-2019; Published Online 26-08-2019)

* Corresponding author

\begin{abstract}
Orchids are known for their aesthetic qualities, and they are often used as decorative items in homes, offices, and public places. While most people admire them for their good looks, others have found practical uses for them. Since a long time ago, people from various parts of the world have used orchids for medicinal purposes. However, the use of orchids in medicine has declined over the years because not enough research has been done to determine their effectiveness and adverse effects.
\end{abstract}

Key words: Medicinal, orchids, Dendrobium

\section{Introduction}

Dendrobium is the second largest genus in the family Orchidaceae. It exhibits a vast diversity in vegetative and floral characteristics and is of considerable interest due to its broad geographic distribution and high value of hybrids as a floricultural commodity (Hawkes, 1970; Jones et al., 1998). The stems of the Dendrobium species, also known as Shih-hu (Japanese: sekkoku; English: Dendrobium stem), are used in traditional Chinese medicine as a tonic to improve digestion and for promoting the production of body fluid, nourishing 'yin' and eliminating 'evil-heat' (Yen, 1980; Anonymous, 1999). 'Shih' means rock and 'hu' means living and signifies the plant living on rocks, referring to the saxicolous habit of the species $(\mathrm{Hu}, 1970)$. It was first recorded in Shen-NungBen-Cao-Jing (the earliest Chinese medicine herbs book, published more than $1900 \mathrm{yr}$ ago) under the 'Inferior Category' and was also recorded in the successive Pen-ts'aos of the subsequent dynasties (Anonymous, 1999). Shi-hu is derived from the stems of the five orchids belonging to the genus Dendrobium , namely, D. chrysanthum, D. fimbriatum, D. loddigesii, D. nobile, and D. candidum (Lau et al., 2001). The main classes of chemical compounds in Dendrobium are a group of sesquiterpene alkaloids (Tang and Eisenbrand, 1992). In the local markets in Taiwan and China, the dried drug costs about US\$4000 kg21 D. candidum (Chinese: Tiepi-shih-hu; 2n 1/4 38) (Withner, 1974) is an epiphyte. Its stems are terete and clustered, and about $35 \mathrm{~cm}$ long and $2-4 \mathrm{~mm}$ in diameter. Leaves are oblong to lanceolate, 4-7 cm long, 1-1.5 $\mathrm{cm}$ wide, and chartaceous. The upper flowers (usually around $2-3$ in number), size about $2-4 \mathrm{~cm}$ in length produced from upper leafless stem are slightly fragrant, and the sepals and petals are white in color (Hawkes, 1970). The lip is egglanceolate, white, obscurely three-lobed, but olive-green in the wider median parts. Flowering usually occurs during the period between April and June (Hawkes, 1970; Anonymous, 1999). The growth habit is similar to that of $D$. aduncum Wall. (Hawkes, 1970). Its external shape is similar to $D$. moniliforme (L.) Sw., which is an indigenous species widely distributed in Taiwan (Lin, 1975). D. candidum is native to the regions of Southern China. In the mountain ranges of YunNan, Guang-Xi, Gui-Zhou, and Fu-Jian provinces of China, this species is distributed at an elevation of $900-1500 \mathrm{~m}$ above sea level, with an annual average temperature of $12-188 \mathrm{C}$ and $1100-1500 \mathrm{~mm}$ annual rainfall. The plant usually requires 5-7 yr of growth before it can be used as a drug. In 1998, the production of $D$. candidum in Yun-Nan was estimated to be less than $1000 \mathrm{~kg}$ (Fu et al., 1999). Tissue culture methods have been used for conservation and vegetative propagation of many important plant species (Fay, 1992). In vitro propagation of $\quad$ D. antennathum and D. phalaenopsis has been reported previously (Kukulczanka and Wojciechowska, 1983) and a high rate of shoot proliferation could also be induced from shoot segments of three epiphytic orchids (Nayak et al., 1997). In D. candidum, micropropagation has been achieved using embryo, protocorm, immature seeds, and shoot tip explants (Liu et al., 1988; Zhang et al., 1992, 1993; Guo et al., 1996). Other studies on D. candidum have also been reported. They include analysis of amino acids in fresh plants (Huang and Ruan, 1997), polysaccharide determination from seedlings and calli (Huang and Lu, 1998; *Author to whom correspondence should be addressed: Email hstsay@ mail.cyut.edu.tw Yi et al., 1999) and seedling development in vitro (Liu and Zhang, 1998). However, to the best of our knowledge, there is no report on the clonal propagation of $D$. candidum using axillary nodal segments. In this study, we report the development of an efficient and simple protocol for rapid propagation using axenic nodal segments of $D$. candidum.

\section{Dendrobium nobile benefits}

For thousands of years, people in south China will risk their lives to pick the "immortality herb" grown in the edge of cliffs for saving patients in critical condition. You might have guessed by now that the herb mentioned is called Dendrobium . In the legends, the juice of it can resurrect the dead. Of course, this is just a legendary saying but can offer another 
perspective on reviews of its rarity and efficacy. Otherwise, it wouldn't be called as "gold in medicine". Besides, it is highly regarded as the No. 1 of the 9 "Chinese immortality herbs", which refers to Tie $\mathrm{Pi}$ Shi $\mathrm{Hu}$ (Dendrobium candidum), Tian Shan Xue Lian (Saussurea involucrate from Tian Shan Mountain), San Liang Zhong Ren Shen (three liang of ginseng), one-hundred-and-twenty-year He Shou $\mathrm{Wu}, \mathrm{Fu}$ Ling (Poria of a cycle of sixty years), Cong Rong (Cistanche), Shen Shan Ling Zhi (Ganoderma in remote mountains), Hai Di Zhen Zhu (seabed pearls), and Dong Chong Xia Cao (Cordyceps Sinensis). And its top 10 main health benefits are as follows:

1) Nourishing Yin and body fluid. The "China Pharmaceutical Dictionary" claims that it is specialized at nourishing qi and fluid in lung and stomach. Hence, it treats a variety of diseases caused by deficiency of yin and body fluid;

2) Enhancing physical fitness. Yao Xing Lun (A book on pharmacological nature of drugs) argues that it can tonify kidney essence, nourish the stomach Yin, and increase strength. And it is rich in polysaccharides that enhance immune function;

3) Replenishing spleen and stomach. It is a commonly used drug for stomachache and epigastric pain. And modern medical experiments confirmed that it has a better inhibition on the pathogen Helicobacter pylori that is frequently found in spleen and stomach diseases, such as atrophic gastritis, superficial gastritis, duodenal ulcer, and more;

4) Protecting liver and gallbladder. It has a good choleretic effect, which has been praised highly by many herbalists. As a result, it is often used as a major medicine for the treatment of hepatobiliary diseases, such as hepatitis, cholecystitis, gallstones and others;

5) Strengthening tendons and lowering lipid. The secretion of Yin fluid and function of bone and muscle would begin to gradually decrease during the middle ages. Since it can nourish Yin fluid and lubricate joints, it helps to strengthen tendons and bones, relieve joint pain, and reduce rheumatism. And modern pharmacological research also showed that it can improve stress ability, prevent or stop fatigue, increase hypoxia tolerance, promote circulation, dilate blood vessels, and lower blood cholesterol and triglycerides;

6) Lowing blood sugar. It has long been used as the specific drug for diabetes since ancient times thanks to its ability of nourishing yin, clearing heat, and moistening dryness. Clinical studies have shown that it cannot only enhance activity of insulin, but also significantly reduce and change blood sugar levels back to normal;

7) Inhibiting tumor. It kills some certain cells of malignancies, such as lung cancer, ovarian cancer, and promyelocytic leukemia. Since it has strong anti-tumor activity, clinically it is often used as the adjuvant treatment of malignant tumors. In other words, it can improve symptoms of cancer patients, reduce side effects of chemotherapy and radiotherapy, enhance immunity, improve quality of life, and prolong survival time;

8) Improving eyesight. It was also viewed as one of the best eye tonics in the eyes of ancient physicians because of its yin-nourishing and eyesight-improving properties. And modern pharmacological studies confirmed that it could make a difference on the prevention and treatment of senile cataract and children's eyesight;

9) Nourishing the skin. Due to dwindling Yin fluid in body, the aging of skin speeds up in people in middle age. Therefore, the skin begins to turn black and become wrinkle. This is where the Dendrobium gets in since the mucus it contains can moisturize and provide nutrition to the skin;

10) Prolonging life. The "Shen Nong's Herbal Classic" reviews that it is an effective medicine that can help weight loss and longevity. Modern pharmacological studies confirmed that it contains many trace elements, which are closely related to human health and longevity. Hence, it has more comprehensive anti-aging effect compared to other herbs.

\section{Dendrobium s recipes on herbal remedies}

The Chinese Materia Medica thinks that it is sweet in flavor and slightly cold in nature. It goes to meridians of stomach, lung, and kidney. Essential Dendrobium nobile effects and functions are promoting the secretion of body fluid, benefiting the stomach, nourishing yin and clearing heat, moistening lung and tonifying kidney, improving eyesight, and strengthening lower back. Basic Dendrobium nobile uses include fever-induced impaired fluid, dry mouth, polydipsia, deficient stomach-yin, stomach pain and retching, dry cough due to lung dryness, persistent deficient heat, dim eyesight caused by yin impairment, and weak waist and knees. Recommended Dendrobium nobile dosage is from 6 to 15 grams of dried form or 12 to 30 grams of fresh herb in decoction. Besides, it is also available in a variety of other forms, such as Dendrobium nobile supplement, pills, extract, powder, paste, tea, and more.

1) Qing Re Bao Jing Fa from Shi Bing Lun (Treatise on Seasonal Diseases). It is formulated with Tian Hua Fen (Trichosanthes Root), and Xian Sheng Di (Fresh Rehmannia Glutinosa), Mai Men Dong (Ophiopogon Tuber), etc. to treat impaired fluid due to fever, thirst, dry tongue, and blacking coating.

2) Shi Hu Ye Guang Wan from Yuan Ji Qi Wei(Orthodox Ophthalmology: Revealing the Mystery of Eye Disease). It is combined with Gou Qi Zi (Goji Berry), Shu Di Huang (Rehmannia Root), Tu Si Zi (Cuscuta), etc. to cure dim eyesight due to kidney-yin deficiency.

3) Qu Fan Yang Wei Tang from Yi Chun Tian Yi. It is matched with Shu Shi Gao (calcined gypsum), Trichosanthes Root, Nan Sha Shen (Adenophora), Mondo Grass, etc. to heal diabetes.

4) Shi Hu San from Sheng Ji Zong Lu (Complete Record of Holy Benevolence). It is coupled with Xian Ling Pi (herba epimedii) and Cang Zhu (Atractylodes) to treat night blindness.

\section{Clinical research of Dendrobium orchid}

According to reports, it is commonly used to treat chronic pharyngitis, thrombosis obliterans, arthritis, purulent skin infections and other diseases. For example, 172 cases of chronic pharyngitis have been treated with the Dendrobium based remedy. The healing steps are decocting the herbal 
combination of Dendrobium 10g, Xuan Shen (Scrophularia) $10 \mathrm{~g}$, Trichosanthes $10 \mathrm{~g}$, and Zao Xiu (manyleaf paris rhizome) for the decoction, purify it by distillation, and let the patients inhale it with ultrasonic atomizing inhalation. And 62 cases were effective and 87 cases were improved. (a)

\section{Dendrobium nobile side effects and contraindications}

Dendrobium nobile herb is with very low toxicity and clinically it tends to be considered non-toxic in regular dosage. However, overdose may cause convulsions, which can be relieved by sodium amytal. Besides, clinically it was ever reported that it had induced allergic dermatitis. From the perspective of traditional Chinese medicine (TCM), it shouldn't be used in cases of unimpaired yin in early stage of febrile disease, damp-warm disorders that are not transformed into dryness yet, and deficiency-cold in spleen and stomach.

\section{Useful Parts of the Plant}

Fresh or dried stems. Blossoms and canes are eaten. Dendrobium is a type of orchid that is generally yellow or pink in color. The plant has a long thin stem that is used for various herbal and medicinal treatments. Dendrobium has been used in traditional Chinese medicine for centuries now. The Chinese believe that the tonic extracted from the Dendrobium plant is 'yin' in nature and can be used to treat ailments ranging from stomach pain, heatstroke, dry mouth and sores in the mouth. Dendrobium can be had in the form of a tea. You can make this at home by leaving 6 to 12 grams of Dendrobium to infuse in hot water before drinking. You can also buy Dendrobium extract or powder from health food stores or from most Asian markets. Dendrobium is considered a safe herb when consumed in the recommended dosages. Too much of Dendrobium in any form can cause convulsions and may even affect the heart and lungs. Research is still being conducted on the interactions of Dendrobium with other drugs or medications. Always consult with your doctor or health care provider before beginning any herbal therapy or remedy.

\section{Health Benefits and Therapeutic Uses of Dendrobium}

In addition to their beauty, Dendrobium orchids have been tested and proven to be an effective herbal treatment for a number of health problems. In fact, the Chinese consider Dendrobium as one of the fifty fundamental herbs used to treat all kinds of ailments.

- Among its many uses, the Chinese use Dendrobium tonic for longevity. It is believed that Dendrobium when mixed with licorice roots and made into a tea transmits healing energy to all parts of the body.

- Dendrobium helps moisten and nourish the skin and prevents dryness and flaky skin.

- When air pollution and smoke dry out the lungs and air passages and increase thirst, Dendrobium can be consumed for quick relief and to moisten the passageways.

- Dendrobium is used as an effective tonic for the treatment of tuberculosis, flatulence, night sweats, anorexia, fever, and dyspepsia.

- Dendrobium tonic improves the functioning of the lungs, kidneys, and stomach. It can reduce stomach pain and cramping and reduce vomiting.

- It is believed that regular consumption of Dendrobium can also treat sexual impotency.

- Pain in the feet and hands, lumbago, and arthralgia can be treated with Dendrobium extract.

- Dendrobium can boost the immune system and help the body fight infections.

- Dendrobium has long since been used to replenish lost fluids from the body and reduce severe thirst.

- Natives of the Eastern Himalayas use Dendrobium to heal problems with the eyes.

Other Uses

- Dendrobium makes ideal houseplants. Along with their pretty colors and decorative qualities, growing Dendrobium s at home can eradicate pollutants and toxins from the air and create a clean environment.

- Dendrobium blossoms and canes are edible. Countries like Thailand and Singapore, deep fry these delicacies and eat them as snacks.

- In Europe, Dendrobium blossoms are used as edible cake decorations and as garnishes.

- The Aborigines consider Dendrobium s as emergency bush food.

- Pickle is made from Dendrobium flowers in Nepal.

\section{Discussion}

Despite the lack of randomized trials, the alkaloids in orchids may have biological actions. Clinical research in man does support dendrobine as a weak anti-pyretic and analgesic. Two medicinal preparations may lower blood sugar and two may lower blood pressure (those containing gastrodin and colchicine). As Bai-Ji is a haemostatic powerful enough to necrotize tumours, this agent has obvious therapeutic use.

A weakness of our conclusions is that Chinese herbal medicines do not have the rigorous characterization and standardization necessary for clinical study. Indeed one product of Tian Ma includes eight other non orchid preparations and is blended according to the Yuen Dynasty Herbal Therapy formulation. Nevertheless, animal experiments support the concept that the active ingredients may have both therapeutic and toxic effects. Hew, Arditti and Lin tried to reconcile Chinese and Western pharmacology by suggesting that the major groupings ( $Q i$ groupings) of Chinese medicines into hot, warm, cool, cold etc may relate to their superoxide producing or scavenging ability. Certainly the Chinese believe that a hot disease should be cooled and vice versa. Shi-Hu is apparently a 'cool' drug used for hot diseases such as fever. It also produces superoxide and may have antimicrobial activity. In contrast Tian-Ma is a 'warm' drug that has anti-oxidant actions and Liu and $\mathrm{Mori}^{34}$ have attributed its claimed antiepileptic activity to this effect. To our knowledge these ideas have not been substantiated, and further research is required.

\section{Dendrobiu}

Shih $\mathrm{Hu}$ (rock living and derives nourishment from the atmosphere) is a term used to describe all Dendrobium and some Flickingeria species in China. There are 1,400 Dendrobium species in China, but only some of them are used as herbs.

The most commonly used species $D$. nobile. It has erect yellowish stems that furrow as they age. The white flowers are fragrant, the sepal is light purple and the enlarged lip-like petal is deep crimson in colour. D. nobile has a broad 
distribution range, including northeast India, south China, Laos is used as a tonic and strengthening medicine. It is reputed to nourish the yin system of the body, imparting longevity and serving as an aphrodisiac. Stems are used to alleviate thirst, calm restlessness, accelerate convalescence and reduce the dryness of the mouth. Shih $\mathrm{Hu}$ is taken as a medication for alleviating gastric, fever, inflammation, pain, and epilepsy. It is also used to treat rheumatism, excessive perspiration, bodily weakness brought about by thirst, vaginal discharge, and menstrual pain. A report has mentioned that it is one of the herbs selected for the first stage of diabetes treatment.

\section{Dendrobium Orchid and Medicinal Uses}

Since ancient times, the Dendrobium nobile has been used in Chinese medicine. The Dendrobium orchid is listed as one of the top 50 herbs used in traditional Chinese medicine. The stems of the Dendrobium orchid are used in herbal remedies. Although fresh stems are sometimes used, in most cases it is the dried stems of the Dendrobium orchid that are preferred. Herbal teas are also made from the stems of Dendrobium orchid. Some of the used of the Dendrobium orchid in traditional Chinese medicine include treatments for boosting the immune system, replenishment of fluids, increasing salivation, dry cough and curing eye ailments. The Dendrobium orchid also has a history of medicinal use in treating pulmonary tuberculosis, impotence, and anorexia. The plant has also been known to moisten and enhance the skin. Supervision from qualified medical doctor is crucial as the Dendrobium orchid in the wrong doses has also been known to have adverse affects on the body.

Dendrobium Sw ( Shih-hu ) Shih-hu is a term used to describe all Dendrobium and some Flickingeria species in China. According to one estimation there are 1400 Dendrobium species in China, but only some of them, especially the Eugenanthe, provide the drug Shihhu in its various forms. The frequently used Shih-hu includes such orchids as Chin chai Shih-hu (Golden Hairpin Dendrobium ), Er Huan Shih-hu (Earring Dendro bium), Ma poen Shih-hu (Horse Whip Dendrobium ), Huan tsao Shih-hu (Yellow Herb Dendrobium ), and Yu kue Shih-hu (Melon Flickingeria). Amo ng them, th e Er Huan Sh ih-hu (Earr ing Dendrobium ), for example, was used as a stomachic in Japan. It was used to treat night sweats in Taiwan, to fortify a person's body, to strengthen the kidneys and to cure impotence. In Korea this species was also employed against impotence, and the entire plant was used as an anti-pyretic, tonic, and peptic. Plants imported into Malaysia by Chinese herbalists were credited as having tonic, stomachic, pectoral, and antiphlogistic properties. By far the most commonly used species in the preparation of Shih-hu is Dendrobium nobile Lindl. This variety of Shih-hu has been valued greatly in China since the Han dynasty (200 BC to $200 \mathrm{AD}$ ). It is used as a tonic and a strengthening medicine. It is also reputed to impart longevity and serve as an aphrodisiac. The stems are used to alleviate thirst, calm restlessness, accelerate convalescence, and reduce dryness of the mouth. Additional properities of Shih-hu are those of a stomachic, pectoral, antiphlogistic, analgesic, and antipyretic medication. It was also used to treat rheumatism, excessive perspiration, weakness brought about by thirst, excessive perspiration, impotence, entropion, insects in the ear, leucorrhea, and menstrual pain.

Dendrobium candidum Wall.ex Lindl.

\section{Description}

This small sized epiphytic orchid grows on tree branches of densely forested areas at an elevation of 2000$3000 \mathrm{~m}$. The stems are terete with oblong to lanceolate green leaves clustering towards the apex. Inflorescence is very short with 2-3 small, scented flowers produced from upper leafless stem. Flowering usually occurs during April and June.

\section{Distribution}

The plants are widely distributed in Taiwan, Southern China, Nepal, Thailand, Vietnam, India and Myanmar. This orchid is normally recorded in Saramati, Japu range and Phek areas of Nagaland.

\section{Medicinal uses}

The leaves are used to prepare aqueous extract which is used for treatment of diabetics. The plant shows antihyperglycemic effect with its mechanism of stimulating secretion of insulin from beta cells and inhibiting secretion of glucagons from cells (Wu_et al., 2004).

Dendrobium chrysanthum Wall. ex Lindl.

\section{Description}

The plants occur as epiphyte on the branches of tall tree or lithophytes on the hard rocks or limestone cliffs in evergreen lowland forest at an elevation of 450-2000 m. The stems are fleshy, cylindrical and pendulous with many internodes covered by leaf sheaths. Leaves are bright shiny, greenish in coloration, numerous and acuminate over the length of stem. The inflorescence is positioned opposite to the leaves with 1-3 fleshy and scented flowers. The flowering takes place in April, August and September.

\section{Distribution}

The plants are distributed widely in North-eastern India, Nepal, Bhutan, Burma, China, Thailand, Laos and Vietnam. The plant grows mostly in the Wokha, Mokokchung, Longkhum and Changki regions of Nagaland.

\section{Medicinal uses}

The leaves of this orchid may be dried and ground to produce the final powdery product which can be used as antipyretic and also for the treatment of some mild skin diseases (Li_et al., 2001). The stem of the plant can be dried and use for enhancing immune system.

Dendrobium chrystoxum Lindl.

\section{Description}

This epiphytic orchid also known as golden orchid grows on the long and large branches of tall trees of deciduous forest at an elevation of 700-1200 m. Pseudobulb is erect, variable in size, thick, fusiform and distinctly grooved enveloped by leathery, persistent, oblong and acute leaves. Inflorescence is arching having 15-20 highly honey fragrant flowers with bright yellow shiny coloration. The flowering time of the orchid is in the month of April and May.

\section{Distribution}

The plant is found widely distributed in North-eastern India, Nepal, Bhutan, Burma, China, Thailand, Laos and 
Vietnam. In Nagaland, the plants are noticed in Julukie, Medziphema, Dzuja and Longlen regions.

\section{Medicinal uses}

The leaves of this plant may be boiled and the resultant liquid extract is used as tonic and antipyretic. Erianthridin which is phenanthrenes extracted from the body of the plant shows anti-inflammatory activities (Yang_et al., 2006).

Dendrobium fimbriatum Hook.

\section{Description}

This large sized orchid grows as epiphyte, lithophytes or terrestrial in dense forest at an elevation of 800-2400 m above sea level. The stems are long, erect, arching, pendulous bearing dark green lanceolate leaves. Racemes have many yellow colored flowers making the plant look more attractive. The flowering takes place in April and May.

\section{Distribution}

The plants are noticed widely in China, Western Himalayas, Bangladesh, Eastern Himalayas, India, Nepal, Bhutan, Laos and Vietnam. The plants are found growing mostly in the Dzuja, Peren, Mokokchung and Wokha regions of Nagaland.

\section{Medicinal uses}

The leaves of the plants may be either boiled or soaked in warm water which can be consumed either as tonic as it promotes the production of body fluid. It can also be applied on fractured areas to set the crack bones.

\section{Dendrobium nobile Lindl.}

\section{Description}

This orchid is either epiphyte or lithophytes growing on the tree trunks and hard flattened rocks in semi deciduous and deciduous forest at an elevation of 200-2000 m. The pseudobulb is erect but becomes pendulous later and swollen at the internodes carrying distichous, strap shaped or oblong persistent leaves. Flowers are white, 2-4 in number, fragrant, long lasting (3-6 weeks) and highly variable. The plant usually flowers in the month of April and May every year.

\section{Distribution}

This important medicinal orchid is distributed mainly in Taiwan, Southern China, Nepal, Thailand, Vietnam, Myanmar and India. The plants are found widely scattered in various areas of Peren, Phek, Kaphire and Noklak regions in Nagaland.

\section{Medicinal uses}

Stems are dried and ground into powders which are then added to water to form aqueous extract which may be used as tonic to nourish stomach and promote the production of body fluid (Liu and Zhao, 2003). In Vietnam, the plant is used in the treatment of pulmonary tuberculosis, general debility, thirsty mouth, night sweats, fever and anorexia (Chauhan, 1999). Medicinal Value of Orchids Since ancient times, orchids have been used all over the world as a source of active substances with therapeutic, hallucinogenic, and aphrodisiac effects. The whole orchid plant, as well as its different parts, especially tubers, roots, rhizomes, stems, pseudobulbs, and leaves, is used in traditional medicine. Invaluable indigenous empirical knowledge about medicinal orchids was discovered independently in time and location across the globe and is still being applied in various forms of traditional medicine today.

The examples of traditional medicine based on orchids are too numerous to be explored in detail here but can be highlighted with a few examples. In Australia, aborigines once used Cymbidium madidum as an oral contraceptive and to treat dysentery (Bulpitt, 2005). In Malawi, native orchids are still used to treat stomach ailments, diabetes, skin infections, and fertility problems (Devenport \& Bytebier, 2004). One concoction, apowder of Cyrtorchis arcuata and an infusion of the dried roots of Eulophia cucullata, curiously enough, is used to promote friendship. In the Americas, Mixteca indigenous people of Oaxaca in southern Mexico have used native orchids such as Prosthechea karwinskii since pre-Hispanic time to treat coughs, wounds, burns, and diabetes as well as to prevent miscarriages and assist in childbirth (Garcia et al., 2014). Even in Europe, where the development of rational Western approaches to medicine in $17_{\text {th }}$ century Europe greatly diminished knowledge about and uses of traditional orchidbased medicines, orchids were used as remedies. For example, in 1640, the English botanist John Parkinson claimed that terrestrial European orchid tubers could increase fertility in human beings (Bulpitt et al., 2007). The greatest number of therapeutic applications derived from orchids comes from Asia, particularly in traditional Chinese medicine (TCM) (Kong et al., 2003; Bulpitt et al., 2007; Gutiérrez, 2010). To the present day, China has a formidable herbal medicine industry many of whose ingredients are based on orchids. For example, "Shi-Hu", which is derived from the 77 Dendrobium species, is considered an important herb for replenishing yin (coldness and moistness). Other orchidbased medicines include Tian-Ma (from Gastrodia elata), Bai-Ji (from Bletilla striata), Jin-Xian-Lian (from the genus Anoectochilus), and Shan-Ci-Gu (mainly from Cremastra appendiculata) (Bulpitt et al., 2007). The traditions of TCM have been disseminated all over Asia, particular in the southeast and east, and everywhere it went, local species were incorporated, thereby expanding the repertoire of ingredients. The ancient Indian system of traditional medicine, Ayurveda, also employs native orchids as ingredients. Asthavarga, a group of eight medicinal plants, half of which are orchids is an important ingredient in many classical formulations. Chavyanprasa, a commonly consumed "delicious nutritive jam" ("Chyawanprash"), is reported to contain four species of orchids, namely, Malaxis muscifera, Malaxis acuminata, Habenaria intermedia, and Habenaria edgeworthi (Singh \& Duggal, 2009). In Nepal, a nation particularly rich in medicinal orchid species due to its immense elevation range, the traditions of TCM and Ayruveda converge. Out of the estimated 450 species of orchids in Nepal, 96 species are said to have an assigned medicinal value (Pant \& Raskoti, 2013). The global market for herbal supplements and remedies, including those used in TCM, is forecast to continue to grow robustly and could reach USD 115 billion by 2020. Europe is the largest market and Asia-Pacific, the fastest-growing. The demand is driven by women as the main consumers, by a growing emphasis on healthy living, and by concerns about the side-effects of mainstream drugs (Rinaldi \& Shetty, 2015). Figure 1: a) Tubers of Habenaria intermedia used in traditional medicines (Source: Pant and Raskoti, 2013); b) Preparing traditional medicine from orchids. a b 88 Despite the fact 
that collective traditional knowledge about native orchids is substantial, the exploitation of natural products from orchids for their therapeutic use, either as an active pharmaceutical ingredient or as a starting point for novel lead structures in structure-based activity studies designed to optimize clinical usage by designating appropriate efficacy and safety margins, has been limited (Bulpitt et al., 2007; Hossain, 2011). That said, modern medicine is desperately short of new treatments due to stagnating creativity in pharmaceutical research and development despite its many new and sophisticated technologies; rising drug resistance; and an increasing regulatory burden, which has caused research and development costs and timelines to skyrocket. Increasingly, nature's portfolio and the trove of traditional medicines are being revisited as sources for new therapies and used in combination with approaches like reverse pharmacology, ethnobotany, systems biology, genome mining, high-throughput screening, proteomics and metabolomics, as well as, conventional drug-discovery technologies (Rinaldi \& Shetty, 2015; Prasad \& Tyagi, 2015). This revived interest in and urgent need for plantbased medicines may foster continued research into candidates for modern pharmaceuticals, including orchids, and may increasingly value the know-how of traditional medicine regarding their usage. To develop modern pharmaceuticals from medicinal orchids, the following steps must be taken: (a) identify active compounds and their drug targets by using structure-based activity studies; (b) optimize those compounds identified thus far by conducting appropriate safety and toxicity studies and fixing first-inhuman dosages so that the compounds can become leads in the pre-clinical stage; and (c) conduct randomized doubleblinded controlled clinical trials for safety and efficacy assessments in humans which follow evidence based practices and meet all regulatory, including ethical requirements. The therapeutic applications of the substances derived from medicinal orchids are many and vast: the substances serve as analgesics (alleviating muscular pain, chest pain, earaches, and pains associated with wounds, bone fractures, and sores), antidotes (against snake and scorpion bites), antihelminthics, aphrodisiacs, emetics, and laxatives; treat conditions like diabetes and other metabolic disorders, infectious diseases (including cholera, folliculitis, malaria, tuberculosis, and syphilis and other sexually transmitted diseases), and pulmonary and other respiratory diseases (including asthma and COPD), and internal diseases; and are applied in the fields of dermatology (to treat eczema and leucoderma), gastroenterology (to treat hemorrhoids, diarrhea, dysentery, dyspepsia, and other stomach disorders), hepatology (to treat jaundice and hepatitis), neurology (to treat 99 paralysis), oncology (to treat cancer), rheumatology (to treat arthritis and rheumatism), and women's health (to prevent contraception and treat menstrual disorders) (Zhao et al., 2003; Yang et al., 2006; Zhang et al., 2006; Gutiérrez, 2010; Hossain, 2011). Figure 2: It's a long way from an idea to a medicine: it takes about 15 years to narrow thousands of compounds to hundreds to a few and, finally, to just one product. (Courtesy: Dr. Stacie Canan) Orchids offer an arsenal of bioactive compounds, including secondary metabolites (alkaloids, terpenoids, glycosides, phenols, and large molecules), signal compounds (scent and color), phytoalexins (orchinol and hircinol), and endogenous phytohormones and regulators. Drug development requires that the bioactive compounds of a plant be isolated
However, in some cases, crude mixtures may show activity only if individual constituents act synergistically, thereby complicating the process of identification. By identifying the active compound structure of a given orchid species and potentially synthesizing it, we may be able to preserve valuable orchid species from present and future overexploitation as once we have a synthetic compound that is equally or more efficacious than that produced by an orchid in the wild, then demand for that wild species will naturally plummet. That said, the profiling of the phytochemistry of orchids, and, more specifically, the pharmacological evaluation of their biological activity against interesting drug targets is still in its infancy. 1010 Phytochemical profiling has been conducted mainly on species used for traditional medicinal purposes, including orchids which originate in India, and has resulted in the isolation of polyphenols, ligans, alkaloids, monoterpenes, triterpenes, stilbenoids, bibenzyls, and phenanthrenes (Garo et al., 2007). Pharmacological research on the orchids used in TCM has focused heavily on the Dendrobium species. The biological data thus far reported regarding the active compounds of TCM orchids, however, is sadly deficient: often no active compound has been identified at all, and, if one has, either no mechanism of action has been pinpointed or there are no substantiated efficacy data in complex biological systems like rodents. Since a comprehensive discussion of other efforts in phytochemical profiling is beyond the scope of this book, see Kong et al. (2003), Gutiérrez (2010); and Chinsamy (2012), and Lam et al. (2015) for information about the in vitro activity of cellular assay results for bioactive compounds derived from medicinal orchids. Not all research has been as unenlightening as that on TCM orchids, however, and some trials have been conducted on small mammals. For example, Vergara-Galicia et al. (2013) demonstrated the vaso-relaxant effect of bioactive compounds from Laelia species in a rat model, and Porte et al. (2014) recently reported that an orchid-derived compound exhibited cellular activity useful for treating ovary sarcoma. Sharma et al. (2015) demonstrated that Pholidota articulata Lindl., an orchid which contains oxoflavidin, a substance with osteogenic properties, promoted the healing of fractures in a mice model. Dendrobium species have also shown potential. Wang et al. (2015), after carrying out principal component analysis, tested the efficacy of Dendrobium candidum in treating constipation in mice model and $\mathrm{Wu}$ et al. (2014) investigated Dendrobium tosaense as a treatment for atopic dermatitis, also in mice. Some bioactive compounds in orchids may exhibit undesired side effects. For example, the 1,2- and 1,4-phenanthrenequinones found in some orchids are allergens. In fact, botanists who collected lady's slippers (orchids in the subfamily Cypripedioideae) described getting contact dermatitis of the hands and the face as early as 1875 (Babcock) and 1894 (MacDouglas) (Babcock, 1875; MacDouglas, 1894). A century later, the allergic 1,4phenanthrenequinone cypripedine was isolated from Cypripedium calceolus (Schmalle \& Hausen, 1979). Taken internally, overdoses of Cypripedium preparations can cause hallucinations (Grieve, 1998). Despite the fact that research into medicinal orchids has intensified and made progress, particularly in China and India, so far no formal pre-clinical candidate has been described in the literature. Linking indigenous 1111 knowledge about medicinal orchids with modern research activities will provide a new avenue for the 
discovery of novel drugs that successfully meet the demands of patients and their doctors. Before we can even speak of a promising future for evidence-based pharmaceutics rooted in medicinal orchids, however, we must conduct extensive and multidisciplinary research they may also help boost the immune system.

\section{Conclusion}

The original impression, that orchids have no use in medicine, is not fully supported by an examination of the use of Chinese orchids. However, with the exception of Bai-Ji, we are lacking proof of efficacy from controlled studies, and we lack precise ingredients and standardization. We also lack information on safety, and the interactions between herbal medicines and 'western' medicines are legendary. The jury remains out on the use of Chinese orchid medicines.

\section{References}

Aggarwal S, LW Zettler (2010). Reintroduction of an endangered terrestrial orchid, Dactylorhiza hatagirea (D. Don) Soo, assisted by symbiotic seed germination: First report from the Indian subcontinent. Nat. Sci. 8(10):139145.

Arditti J (1967). Factors affecting the germination of orchid seeds. Bot. Rev. 33:1-97.

Arditti J (1968). Germination and growth of orchids on banana fruit tissue and some of its extracts. Am. Orchid Soc. Bull. 37:112-116.

Arditti J (1992). Fundamentals of Orchid Biology. John Wiley \& Sons,New York.

Arditti J, Clementsm MA, Fast G, Hadley G and Nishimura, G (1982). Orchid seed germination and seedling cultureA manual. In: Orchid Biology-Reviews and perspectives, Vol II, Arditti J (Ed.), Cornell University Press, Ithaca, New York. pp. 243-370.

Arditti J, Ernst R (1984). Physiology of orchid seed germination. In: Arditti J (ed) Orchid biology: reviews and perspectives, New York.

Badola HK, Pal M (2002). Endangered Medicinal plant in Himachal Pradesh. Curr. Sci. 83:797-798.

Balzarini J, Neyts J, Schols D, Hosoya M, Van Damme E, Peumans W, De Clercq E (1992). The mannose-specific plant lectins from Cymbidium hybrid and Epipactis helleborine and the (Nacetylglucosamine) n-specific plant lectin from Urtica dioica are potent and selective inhibitors of human immunodeficiency virus and cytomegalovirus replication in vitro. Antiviral Res. 18:191-207.

Baral SR, Kurmi PP (2006). A Compendium of Medicinal Plants of Nepal. Publisher Rachana Baral, Printed in Nepal by Mass Printing Press, Kathmandu.

Basker S, Bai VN (2006). Micropropagation of coelogyne stricta (D.Don) Schltr. Via pseudo bulb segment cultures. Trop. Subtrop. Agroecosyst. 6:31-35.

Basu K, Dasgupta B, Bhattacharya S, Lal R, Das P (1971). Anti-inflammatory principles of Vanda roxburghii. Curr. Sci. 40:80-86.
Bechtel H, Cribb P, Launert E (1992). The manual of cultivated orchid species. 3rd ed. Blandford Press, London.

Berliocchi L (2004). In: Griffiths M, editor.The orchid in lore and legend.Portland, Oregon: Timber Press.

Bulpitt C (2005). The uses and misuses of orchids in medicine. QJM 98:625-631.

Chang C, Chang WC (2000). Micropropagation of Cymbidium ensifolium var. misericors through callusderived rhizomes. In vitro Cell. Dev. Bio. Plant. 36:517520 .

Chang, C, Chang, WC (2000). Effect of thidiazuron on bud development of Cymbidium sinense Willd in vitro. Plant Growth Regul. 30:171-175.

Chaudhary R, Subedi A, Shakya L, Karki D, Vetass O, Gupta V (2002).Orchid diversity in Arun river and Marsyagdi river basins of Nepal:distribution and conservation priorities. Vegetation and society: their interaction in the Himalayas pp.108-117.

Chen CC, Wu LG, Ko FN, Teng CM (1994). Antiplatelet aggregation principles of Dendrobium loddigesii. J. Nat. Prod. 57:1271-1274.

Chen JT, Chang WC (2003). 1-Aminocyclopropane-1carboxylic acid enhanced direct somatic embryogenesis from Oncidium leaf cultures.Biol. Plant 46:455-458.

Chugh S, Guha S, Rao IU (2009). Micropropagation of orchids: a review on the potential of different explants. Scientia Horticulture 122:507-520.

Cribb P (1997). The genus Cypripedium. Portland, Oregon: Timber Press; p.301.

Datta K, Kanjilal B, De Sarker D (1999). Artificial seed technology:Development of a protocol in Geodorum densiflorum (Lam) Schltr.-An endangered orchid. Curr. Sci. 76:1142-1144.

Deb CR, Temjensangba S (2006). Effect of different factors on non- symbiotic seed germination, formation of protocorm-like bodies and plantlet morphology of Cleisostoma racemiferum (Lindl.) Garay.Indian J. Biotechnol. 5:223

Deb CR, Pongener A (2012). Studies on the in vitro regenerative competence of aerial roots of two horticultural important Cymbidium species. J. Plant Biochem. Biotechnol 6:1-7.

Dixon KW (2003). Orchid conservation. Natural History Publications (Borneo).

Dressler RL (1993). Phylogeny and classification of the orchid family: Cambridge University Press.

Duke JA, Bogenschutz-Godwin M, Cellier J (2002). Handbook of medicinal herbs: Boca Raton, Florida CRC.

Ernst R (1982). Orchid seed germination and seedling culturea manual: Paphiopedilum. Orchid Biol. Rev. Perspect. 2:350-353.

Fujii J, Slade A, Redenbaugh K (1989). Maturation and greenhouse planting of alfalfa artificial seeds. In vitro Cell Dev. Biol. 25:1179. 
Ghanaksh A, Kaushik P (1999). Antibacterial effect of Aerides multiflora Roxb.: a study in vitro. J. Orchid Soc. India 13:65-68.

Giri D, Arya D, Tamta S, Tewari LM (2008). Dwindling of an endangered orchid Dactylorhiza hatagirea (D. Don) Soo: A case study from Tungnath Alpine meadows of Garhwal Himalaya. India. Natl. Sci. 6:6-9.

Gutiérrez RMP (2010). Orchids: A review of uses in traditional medicine, its phytochemistry and pharmacology. J. Med. Plants. Res. 4:592- 638.

Hernández-Romero Y, Acevedo L, Sánchez MLÁ, Shier WT, Abbas HK, Mata R (2005). Phytotoxic activity of bibenzyl derivatives from the orchid Epidendrum rigidum. J. Agric. Food. Chem. 53:6276-6280.

Hew CS, Arditti J, Lin WS (1997). Orchid cut-flower production in ASEAN countries. In: Arditti, J(Ed.), Orchid Biol. Rev. Perspect. 6:363-401.

Hossain MM (2011). Therapeutic orchids: traditional uses and recent advances-An overview. Fitoterapia 82:102-140.

Hossain MM, Sharma M, Pathak P (2009). Cost effective protocol for in vitro mass propagation of Cymbidium aloifolium (L.) Sw.-a medicinally important orchid. Eng. Life. Sci. 9:444-453.

Hossain MM, Sharma M, Pathak P (2012). In vitro propagation of Dendrobium aphyllum (Orchidaceae)seed germination to flowering. J. Plant Biochem. Biotechnol. pp.1-6.

Hua L, Zhiguo Z (1998). Studies on plantlet strengthening medium for Dendrobium candidum Wall. et Linde. of clonal propagation in vitro. China J. Chin. Mater. Med. 11:654-655

Jalal JS, Kumar P, Pangtey Y (2008). Ethnomedicinal Orchids of Uttarakhand, Western Himalaya. Ethnobotanical Leaflets 2008:164.

Johnson TR, Stewart SL, Dutra D, Kane ME, Richardson L (2007). Asymbiotic and symbiotic seed germination of Eulophia alta (Orchidaceae)-preliminary evidence for the symbiotic culture advantage. Plant Cell Tiss. Org. Cult. 90:313-323.

Jonn SD (1988). Simple medium for regeneration of Pclb's of Debdrobium walter Oumae. Bull. Penelitian Hort. 16:7378.

Joshi KK, Joshi SD (2000). Genetic Heritage of Medicinal and Aromatic Plants of Nepal Himalayas. Buddha Academy Publisher and Distributors, Pvt. Kathmandu, Nepal.

Joshi G, Tewari LM, Lohani N, Upreti K, Jalal JS, Tewari G (2009). Diversity of orchids on Uttarakhand and their conservation strategy with special reference to their medicinal importance. Rep. Opin. 1:47-52.

Kala C (2004). Assessment of species rarity. Curr. Sci. 86:1058-1058. Kanjilal B, Sarker DDE, Mitra J, Datta KB (1999). Stem disc culture: Development of a rapid mass propagation method for Dendrobium moschatum (Buch.-Ham.) Swartz- An endangered orchid. Curr. Sci. 77:497-500.
Kasulo V, Mwabumba L, Munthali C (2009). A review of edible orchids in Malawi. J. Hortic. For. 1:133-139.

Kaur S, Bhutani K (2011). Micropropagation of Malaxis acuminata D. Don: A Rare Orchid of High Therapeutic Value. Open Access J. Med. Aromat. Plants 1:29-33.

Khan M, Omoloso A (2004). Antibacterial activity of Galeola foliata. Fitoterapia 75:494-496.

Khasim S, Rao PRM (1999). Medicinal importance of orchids. The Botanica 49:86-91.

Knudson L (1922). Nonsymbiotic germination of orchid seeds. Botanical Gazette: pp.1-25.

Knudson L (1925). Physiological study of the symbiotic germination of orchid seeds. Bot Gaz 79:345-379.

Knudson L (1927). Symbiosis and asymbiosis relative to orchids. New Phytol. 26:328-336. 466 Afr. J. Plant Sci.

Knudson L (1946). A nutrient for germination of orchid seeds. Am. Orchid Soc. Bull.15:214-217.

Kong JM, Goh NK, Chia LS, Chia TF (2003). Recent advances in traditional plant drugs and orchids. Acta Pharmacologica Sinica 24:7- 21.

Kumar PKS, Subramoniam A, Pushpangadan P (2000). Aphrodisiacactivity of Vanda tessellata (Roxb.) Hook. ex Don extract in male mice. Ind. J. Pharma. 32:300-304.

Langham W (1579). The garden of health; London. Lawler L, Slaytor M (1970). Uses of Australian orchids by Aborigines and early settlers. The Medical journal of Australia 2:1259.

Lesar H, Hlebec B, Čeranic N, Kasteles D, Luthar Z (2012). Acclimatization of terrestrial orchid Bletilla striata Rchb.f.(Orchidaceae) propagated under in vitro conditions. Acta agriculturae Slovenica, 99(1):69- 75.

Li H, Yan Z, Zhou Z, Xu L, Daikonya A, Wang J (2006). Anti-allergic agents from natural sources. Heterocycles 68:1259-1265.

Li M, Zou D (1995). Study on pharmacology activity of Anoectochilus roxburghii from three sources. Information Chin. Pharmacol. Soc. 3:26-28.

Li YM, Wang HY, Liu GQ (2001). Erianin induces apoptosis in human leukemia HL-60 cells. Acta Pharmacologica Sinica 22:1018.

Liu H, Zhang Z (1998). Studies on plantlet strengthening medium for Dendrobium candidum Wall ex. Lindl. clonal propagation in vitro. Zhongyuo Zhongyuo Zachi 23(11):654-656.

Luo H, Lin S, Ren F, Wu L, Chen L, Sun Y (2007). Antioxidant and antimicrobial capacity of Chinese medicinal herb extracts in raw sheep meat. J. Food Protect. 70:1440-1445.

Majumder P, Banerjee S, Sen S (1996). Three stilbenoids from the orchid Agrostophyllum callosum. Phytochem. 42:847-852.

Majumder P, Sen R (1991). Pendulin, a polyoxygenated phenanthrene derivative from the orchid Cymbidium pendulum. Phytochem. 30:2432-2434. 
Manandhar NP (2002). Plants and People of Nepal. Timber Press, Portland, Oregon, USA.

Mazumder PB, Sharma GD, Dutta M, Choudhury DN, Das T, Mazumder B (2010). In vitro propagation and phytochemical screening of Papilionanthe teres (Roxb.) Schltr. Assam University, J. Sci. Technol. Biol. Environ. Sci. 5(1):37-42.

Medhi R, Chakrabarti S (2009). Traditional knowledge of NE people on conservation of wild orchids. Indian J. Trad. Knowl. 8:11-16.

Mitra G (1971). Studies on seeds, shoot tips and stem discs of an orchid grown in aseptic culture. Indian J. Exp. Biol 9:79-85.

Mitra G (1986). In vitro culture of orchid seeds for obtaining seedlings.Biology, conservation, and culture of orchids East-West Press.

Miyazawa M, Shimamura H, Nakamura S, Sugiura W, Kosaka H,Kameoka H (1999). Moscatilin from Dendrobium nobile, a naturally occurring bibenzyl compound with potential antimutagenic activity. J.Agric. Food Chem. 47:2163-2167.

Moerman D (1986). Medicinal plants of the Native Americans. University of Michigan Museum of Anthropology technical report, number 19.University of Michigan. p. 534.

Moerman DE (1998). Native american ethnobotany. Timber Press Portland,

Morel G (1960). Producing virus-free Cymbidiums; Am. Orchid Soc. Bull 29:495-497.

Morris B (2003). Children of the Wind-Orchids as Medicines in Malawi. The Orchid Review, 111:271-277.

Murashige T, Skoog F (1962). A revised medium for rapid growth and bio assays with tobacco tissue cultures. Physiol. Plant. 15:473-497.

Nalawade SM, Sagare AP, Lee CY, Kao CL, Tsay HS (2003). Studies on tissue culture of Chinese medicinal plant resources in Taiwan and their sustainable utilization Bot. Bull. Acad. Sin. 44:79-98.

Nayak NR, Chand PK, Rath SP, Patnaik SN (1998). Influence of some plant growth regulators on the growth and organogenesis of Cymbidium aloifolium (L.) Sw. seed derived rhizomes in vitro. In vitro Cell. Dev. Biol. Plant. 34:185-188.

Nongdam P, Chongtham N (2011). In vitro rapid propagation of Cymbidium aloifolium (L.) Sw.: A medicinally important orchid via seed culture. J. Biol. Sci. 11:254260.

Okamoto T, Natsume M, Onaka T, Uchmaru F, Shimizu M (1966). The structure of dendramine (6-oxydendrobine) and 6-oxydendroxine.The fourth and fifth alkaloid from Dendrobium nobile. Chem. Pharm. Bull.14:676-680.

Pant B, Chaudhary RP, Subedi A, Shakya LR (2002). Nepalese Himalayan Orchids and the conservation priorities. In :Proceeding ofInternational Seminar on Mountains. Royal Nepal Acad. Sci. Technol.pp. 485-495.

Pant B, Gurung R (2005). In vitro seed germination and seedling development in Aerides odorata Lour. J. Orchid Soc. India 19:51-55.

Pant B, Swar S, Gurung, R (2007). Current Status and ex situ conservation of threatened orchids of Nepal. In:Proceedings 9th Asia Pacific Orchid Conference (APOC 9), Seol, Korea. pp.307-318.

Pant B (2008). Application of tissue culture for conservation of medicinal plants. In:PK. Jha et al (eds). Medicinal plants in Nepal:An anthology of contemporary research, Publisher, Ecological Society (ECOS) Kathmandu Nepal. pp. 240-245.

Pant B, Swar S, Karanjeet A (2008). Micropropagation of Coelogyne cristata Lindl. The Journal of Orchid Society of India. 22(1,2):45-48.

Pant B, Shrestha S, Pradhan S (2011). In vitro seed germination and seedling development of Phaius tancarvilleae (L’Her.) Blume. Scientific World 9:50-52.

Pant B, Thapa D (2012). In vitro mass propagation of an epiphytic orchid, Dendrobium primulinum Lindl. through shoot tip culture. Afr. J.Biotechnol. 11:9970-9974.

Pant B, Raskoti BB (2013). Medicinal Orchids of Nepal. Himalayan Map House, Pvt. Ltd. (Publisher).

Paudel MR, Pant B (2012). In vitro plant regeneration of Esmeralda clarkei Rchb. f. via protocorm explant. Afr. J. Biotechnol. 11:11704 -11708.

Pongener A, Deb CR (2011). In vitro regeneration of plantlets of Cymbidium iridioides D. Don using nodal segments as explants. Int. J. Appl. Biotechnol. Biochem. 1(4):389400.

Pradhan S, Pant B (2010). In vitro seed germination in Cymbidium elegans Lindl. and Dendrobium densiflorum Lindl. Ex Wall.(Orchidaceae). Botanica Orientalis: J.Plant Sci. 6:100-102.

Pradhan S, Paudel YP, Pant B (2013). Efficient regeneration of plants from shoot tip explants of Dendrobium densiflorum Lindl., a medicinal orchid. Afr. J. Biotechnol. 12(12):1378-1383.

Prasad DN, Achari G (1966). A study of anti-arthritic action of Vanda roxburghii in albino rats. J. Indian Med. Assoc. 46:234-237.

Puri H (1970). Salep-the drug from orchids. Bull. Am. Orchid Soc. p.39.

Rao A (1977). Tissue culture in the orchid industry. Applied and Fundamental Aspects of Plant Cell Tissue and Organ Culture. J. Reinert and YPS Bajaj (eds.). McGraw-Hill, New York:pp.44-69.

Reinikka MA (1995). A history of the Orchid. Portland Timber Press.

Richards J , Cribb P (1998). The genus Cypripedium. Royal Botanic Gardens, Kew Botanical Magazine Monograph. Timber Press, Portland, Oregon.

Rederbangh K, Fujii JA, Slade D (1993). Hydrated coatings of synthetic seeds. In: Synseeds (Ed.): K.Redenbaugh. CRC Press, Boca Raton. pp.35-46.

Sharma U, Rama R, Mohan J, Reddy A (2007). In vitro 
propagation of Dendrobium microbulbon A. Rich a rare ethnomedicinal herb. Indian J. Biotechnol. 6:381-384.

Sharma N, Chandel KPS (1996). In vitro conservation of Orchis latifolia: A threatened, medicinal terrestrial orchid Indian J. Plant Genet. Res. 9:109-113.

Shimura H, Matsuura M, Takada N, Koda Y (2007). An antifungal compound involved in symbiotic germination of Cypripedium macranthos var. rebunense (Orchidaceae). Phytochem. 68:1442-1447.

Shiau YJ, Nalawade SM, Hsia CN, Mulabagal V, Tsay HS ( 2005). In vitro propagation of Chinese medicinal plant, Dendrobium candidum Wall. Ex. Lindl. from axennic nodal segments. In Vitro Cell. Dev. Biol. Plant. 41:666670 .

Shrestha R (2000). Some medicinal orchids of Nepal. In:The Himalayan plants, can they save us? Proceeding of NepalJapan joint symposium on conservation and utilization of Himalayan medicinal resources (Eds. T. Watanabe, A. Takano, M.S. Bista and H.K. Saiju), Society for the Conservation and Development of Himalayan Medicinal Resources (SCDHMR). pp. 153-156.

Singh A, Duggal S (2009). Medicinal Orchids:An Overview. Ethnobotanical Leaflets, 13:351-363.

Tzeng CM, Yang NS (2004). Induction of apoptosis in MCF7 human breast cancer cells by phytochemicals from Anoectochilus formosanus. J. Biomed. Sci. 11:928-939.

Stewart SL, Kane ME (2006). Asymbiotic seed germination and in vitro seedling development of Habenaria macroceratitis (Orchidaceae), a rare Florida terrestrial orchid. Plant Cell Tiss. Org. Cult. 86:147-158.

Subedi A (2011). New species, pollinator interactions and pharmaceutical potential of Himalayan orchids. Ph.D. Thesis, LeidenUniversity, The Netherlands.

Suresh PK, Subramoniam A, Pushpangadan P (2000). Aphrodisiac activity of Vanda tessellata. Indian $\mathrm{J}$. Pharmacol. 32:300-304.

Swarts N (2007). Integrated conservation of the rare and endangered terrestrial orchid Caladenia huegelii HG Reichb. Ph.D. Thesis, Australia.

Swarts ND, Dixon KW (2009). Terrestrial orchid conservation in the age of extinction. Ann. Bot. 104:543556.

Szlachetko DL (2001). Genera et species Orchidalium. 1. Polish Bot. J. 46:11-26.

Tseng CC, Shang HF, Wang LF, Su B, Hsu CC, Kao HY, Cheng KT (2006). Antitumor and immunostimulating effects of Anoectochilus formosanus Hayata. Phytomed. 13:366-370.

Turner W (1568). The first and seconde partes of the Herbal of William Turner, doctor in Phisick, lately oversene, corrected and enlarged with the Third Parte. Cologne,. (Original publication 1551).

Vacin EF, Went F (1949). Some pH changes in nutrient solutions. Botanical Gazette: pp.605-613.

Vaidya B, Shrestha M, Joshee N (2002). Report on Nepalese orchid species with medicinal properties. Proceeding of Nepal-Japan joint Symposium on conservation and utilization of Himalayan medicinal resources. Society for the Conservation and Development of Himalayan Medicinal Resources (SCDHMR), Japan, pp.146-152.

Vij S (1993). Regeneration response of orchid roots: A study in vitro. J.Orchid Soc. India 7:61-72.

Vij S (2002). Orchids and tissue culture: current status. Role of plant tissue culture. In biodiversity conservation and economic development. Gyanodaya Prakashan, Nainital India. p.491.

Wang J, Matsuzaki K, Kitanaka S (2006). Stilbene derivatives from Pholidota chinensis and their anti-inflammatory activity. Chem. Pharma. Bull. 54:1216-1218.

Sakuma C, Kikuchi H, Shibayama H, Kawai T (2007). Structure of cymbidine A, a monomeric peptidoglycanrelated compound with hypotensive and diuretic activities, isolated from a higher plant, Cymbidium goeringii (Orchidaceae). Chem. Pharma. Bull. 55:780 783.

White KJ, Sharma B (2000). Wild orchids in Nepal: the guide to the Himalayan orchids of the Tribhuvan Rajpath and Chitwan Jungle:Bangkok, Thailand: White Lotus Press .

Williams CA (1979). The leaf flavonoids of the Orchidaceae. Phytochem. 18:803-813.

Wilson MF (2007). Medicinal plant fact sheet:Cypripedium:lady's slipper orchids. Virginia: Arlington.

Wimber D (1963). Clonal multiplication of Cymbidiums through tissue culture of the shoot meristem. Am. Orchid Soc. Bull. 32:105-107. Won JH, Kim JY, Yun KJ, Lee JH, Back NI, Chung HG, Chung SA,

Jeong TS, Choi MS, Lee KT (2006). Gigantol isolated from the whole plants of Cymbidium goeringii inhibits the LPS-induced iNOS and COX- 2 expression via NFkappaB inactivation in RAW 264.7macrophages cells. Planta Med.72:1181-1187.

Yam TW, Arditti J, Cameron KM (2009). "The orchids have been a splendid sport"-an alternative look at Charles Darwin's contribution to orchid biology. Am. J. Bot. 96:2128-2154.

Yang L, Wang Z, Xu L (2006). Simultaneous determination of phenols (Bibenzyl, phenanthrene, and fluorene) in Dendrobium species by high-performance liquid chromatography with diode array detection. J. Chromatogr. A 1104:230-237.

Yi Y, Xing F, Huang X, Chen H, WANG F (2005). Medicinal plants of Bulbophyllum species in China. J. Trop. Subtrop. Bot. 13:65-69.

Zhang D, Zhang Y, Liu G, Zhang J (2006). Dactylorhin B reduces toxic effects of $\beta$-amyloid fragment (25-35) on neuron cells and isolated rat brain mitochondria. Naunyn-Schmiedeberg's Arch. Pharmacol. 374:117-125.

Zhao C, Liu Q, Halaweish F, Shao B, Ye Y, Zhao W (2003).Copacamphane, Picrotoxane, and Alloaromadendrane Sesquiterpene Glycosides and Phenolic Glycosides from Dendrobium moniliforme. J. Nat. Prod. 66:1140-1143. 